\title{
Computational neuroscience in perspective
}

\author{
Antônio-Carlos Guimarães de Almeida, Antônio Márcio Rodrigues, \\ Antonio Fernando Catelli Infantosi
}

Nowadays, the main questions related to brain functions are frequently taken as related to properties of the synaptic circuitry of the different regions which compose the brain structure. This line of thought was naturally influenced by the seminal discoveries starting with Cajal and Golgi (Nobel Prize awarded jointly in 1906), when the synapses were postulated as connections established between neurons. Reinforcing this view, Otto Loewi (1921) was the first to present experimental evidences of the chemical bases for synaptic transmission. Even before the effective discoveries of the mechanisms behind the synaptic transmission, McCulloch and Pitts (1943) showed that simplified neural networks are able to resemble complex properties of the brain. The proposition of the Hebbian theory by Donald Hebb, in 1949, added more enthusiasm to the view of the synaptic circuitry (or neural network) as the solely core of the brain function. Later, a debate led by John Eccles (1953), about the electrical or chemical processes involved in the synaptic transmission, culminated with the elucidation of the role of the acetylcholine as neurotransmitter. At that time, the ionic basis of the neuronal discharges was still under deep investigation and the complex interplay between the sodium and potassium currents demanded a new strategy to describe it. The advanced electrophysiological techniques were not enough to describe an action potential. Hodgkin and Huxley (1952) employed a very complex model, involving non-linear differential equations to represent experimental data and showing the intricate temporal dynamic. In 1973, Bliss and Lomo confirmed the Hebbian theory with experiments performed in the hippocampus region, demonstrating that the chemical synapses could change their strength. All these findings influenced the subsequent development of the neuroscience and the technology. The implementation of cyclic networks with feedbacks between neurons and adjustable synaptic weight provided the configuration of dynamical systems with memory. Improvements of the neural network theory gained more and more attention, with effects that lasted for many years. The neural network theory regains strength and influenced the design of intelligent machines. This atmosphere of thoughts, dominated by the properties of synaptic circuitry as the solely core of the brain function, persists influencing our view about the brain and its mechanisms. The same lines of thoughts are still guiding the different approaches in the investigation of brain pathologies, such as epilepsy. However, a new scenario is becoming evident. The synaptic circuitry view of interfering into the neuronal interconnection with drugs acting in the synaptic neurotransmission is not being successful with the more than $40 \%$ of patients diagnosed with temporal lobe epilepsy. This is the most common type of epilepsy and affects $2 \%$ of the Brazilian population! The main suspicion about the ineffectiveness of the available drugs is that the origin of the seizures does not belong exclusively to the synaptic neuronal interconnectivity, but to the substrate in which the network is immersed and to the nonsynaptic interconnection between the neurons. The substrate is the ionic fluid and the extracellular matrix. Directly affecting the excitability of the neurons is the ionic balance between the intra and extracellular spaces, also known as the ionic homeostasis. Several mechanisms take place in the ionic homeostasis and the interplay between them constitutes a system of high complexity. The $\mathrm{Na} / \mathrm{K}$ pump, co-transporters, exchangers and ionic channels form this system (see computational model description in Almeida et al. (2008)). During seizures or conditions favorable to their disruption, the synchronous discharges of a neuronal population changes the ionic homeostasis, incrementing $\mathrm{K}^{+}$and reducing $\mathrm{Ca}^{++}$at the extracellular space. Under these conditions, it can be presumed that the ionic fluctuation, the electric field effect and the gap-junction are the interconnectors of the neurons. Experiments performed in 1982 give the first support to the importance of the non-synaptic mechanisms for the seizure induction and sustaining (Jefferys and Haas, 1982; Taylor and Dudek, 1982). Epileptiform activities were shown induced in hippocampus slices with solution containing high $\mathrm{K}^{+}$and low $\mathrm{Ca}^{++}$. The difficulties in interpreting experiments where the ionic homeostasis is changing makes necessary the use of computer simulation based on mathematical representation of the neuronal 
network and all mechanisms related to the ionic changes. In large scale, as normally presented in the brain, the complexity of a neuronal population in activity is presumably high. However, what to say about complexity when the neuronal activity is able to change its own environment, changing completely its excitability and interconnectivity? No doubt! The brain is more complex and with even higher information processing capacity than we can imagine. The history of Science has lots of demonstrations that when a problem persists for many years, new strategies are required and new paradigms need to be broken. The scientific community of Biomedical Engineering, intrinsically formed in interdisciplinary concepts, should endeavor to address this kind of problem. But that cannot be preceded only with scientific agreements. We must induce graduate programs to offer courses in interdisciplinary topics of computational neuroscience including the simulation of neuronal-glial networks with synaptic and non-synaptic connections. It is a hot topic to be explored with evident benefits for the treatment of several brain pathologies, like epilepsy, and, of course, the benefits may also impact with technological advances.

\section{References}

Almeida ACG, Rodrigues AM, Scorza FA, Cavalheiro EA, Teixeira HZ, Duarte MA, Silveira GA, Arruda EZ. Mechanistic hypotheses for nonsynaptic epileptiform activity induction and its transition from the interictal to ictal state: computational simulation. Epilepsia. 2008; 49(11):1908-24. PMid:18513350. http://dx.doi.org/10.1111/j.1528-1167.2008.01686.x

Bliss TVP, Lomo T. Long-lasting potentiation of synaptic transmission in the dentate area of the anaesthetized rabbit following stimulation of the perforant path. Journal of Physiology. 1973; 232(2):357-74. PMid:4727085 PMCid:PMC1350459

Eccles JC. The neurophysiological basis of mind: the principles of neurophysiology. Oxford: Clarendon Press; 1953.

Hebb DO. Organization of behavior: a neuropsychological theory medical microbiology. New York: John Wiley and Sons; 1949.

Hodgkin AL, Huxley AF. A quantitative description of membrane current and its application to conduction and excitation in nerve. Journal of Physiology. 1952; 117(4):500-44.

Jefferys JGR, Haas HL. Synchronized bursting of CA1 hippocampal pyramidal cells in the absence of synaptic transmission. Nature. 1982; 300:448-50. http://dx.doi. org/10.1038/300448a0
Loewi O. Über humorale Übertragbarkeit der Herznervenwirkung. II. Mitteilung. Pflügers Archiv: European Journal of Physiology. 1921;193:201-13.

McCulloch WS, Pitts, WH. A logical calculus of the ideas immanent in nervous activity. Bulletin of Mathematical Biophysics. 1943; 5(4):115-33. http://dx.doi.org/10.1007/ BF02478259

Taylor CP, Dudek FE. Synchronous neural afterdischarges in rat hippocampal slices without active chemical synapses. Science. 1982; 218(4574):810-2. http://dx.doi.org/10.1126/ science. 7134978

Antônio-Carlos Guimarães de Almeida, Antônio Márcio Rodrigues - Laboratório de Neurociência Experimental e Computacional, Departamento de Engenharia de Biossistemas, Universidade Federal de São João del-Rei (UFSJ), São João del-Rei, MG, Brazil

Antonio Fernando Catelli Infantosi - Programa de Engenharia Biomédica, Instituto Alberto Luiz Coimbra de Pós-Graduação e Pesquisa de Engenharia (COPPE), Universidade Federal do Rio de Janeiro (UFRJ), Rio de Janeiro, RJ, Brazil 